\title{
Peripheral kisspeptin reverses short photoperiod-induced gonadal regression in Syrian hamsters by promoting GNRH release
}

\author{
L Ansel, A H Bentsen, C Ancel, M Bolborea, P Klosen, J D Mikkelsen ${ }^{1}$ and V Simonneaux \\ Département de Neurobiologie des Rythmes, Institut des Neurosciences Cellulaires et Intégratives (INCI), CNRS UPR \\ 3212, Université de Strasbourg, 5 rue Blaise Pascal, 67084 cedex Strasbourg, France and ${ }^{1}$ Neurobiology Research \\ Unit, Copenhagen University Hospital Rigshospitalet, Copenhagen, Denmark
}

Correspondence should be addressed to V Simonneaux; Email: simonneaux@inci-cnrs.unistra.fr

\begin{abstract}
In seasonal breeders, reproduction is synchronised by day length via the pineal hormone melatonin. In short winter days (short day, SD), the Syrian hamster displays a complete gonadal atrophy together with a marked reduction in expression of kisspeptins (Kp), a family of potent hypothalamic stimulators of GNRH neurons. Both central and peripheral acute injections of Kp have been reported to activate the gonadotropic axis in mammals. The aim of this study was to determine if and how peripheral administration of Kp54 could restore gonadal function in photo-inhibited hamsters. Testicular activity of hamsters kept in SD was reactivated by two daily i.p. injections of Kp54 but not by chronic subcutaneous delivery of the same peptide via mini-pumps. Acute i.p. injection of Kp54-induced FOS (c-Fos) expression in a large number of GNRH neurons and pituitary gonadotrophs together with a strong increase in circulating testosterone. The activation of pituitary cells by Kp was inhibited by preadministration of the GNRH receptor antagonist acyline. Altogether, our results demonstrate that peripheral Kp54 activates the gonadotropic axis by stimulating GNRH release and indicate that an appropriate protocol of long-term systemic Kp administration can recrudesce a photo-inhibited reproductive axis.

Reproduction (2011) 142 417-425
\end{abstract}

\section{Introduction}

Important seasonal variations in environmental parameters such as photoperiod, temperature or hygrometry occur throughout the year. Most seasonal breeders rely on annual changes in photoperiod to restrict their fertility to a particular season, ensuring the birth of the offspring occurs at the most favourable time of year. Thus, transfer of male Syrian hamsters from long days (LD) to short days (SD) inhibits their reproductive activity within 8-10 weeks with a tenfold reduction in testes weight and a dramatic decline in gonadotropins and sex steroid plasma levels (Goldman 2001). Inversely, when animals are transferred back to LD condition reproductive activity is restored within 6 weeks (Goldman 2001). SD-adapted Syrian hamsters constitute an adult model of reversible hypogonadism. Annual variations of the photoperiod are translated into a release of the pineal hormone melatonin, the nocturnal production of which relies on night length. It has been documented that the annual variations of melatonin secretion synchronise reproductive activity to season (Reiter 1980). However, the sites and mechanisms of action of melatonin on the hypothalamo-pituitary-gonadotropic (HPG) axis remain undetermined, and it is unclear whether melatonin acts at a site upstream or downstream of the GNRH neuron. We reported that melatonin inhibits the expression of several hypothalamic genes in the Syrian hamster (Revel et al. 2006a, 2006b, 2008), especially Kiss 1, which is considered to relay the photoperiodic information to the reproductive axis (Simonneaux et al. 2009).

Disruption of either the Kiss1 gene or the KISS1 receptor gene (Kiss1r; formerly referred to as Gpr54) generates a hypogonadic phenotype in mice (Funes et al. 2003, Seminara et al. 2003, d'Anglemont de Tassigny et al. 2007, Lapatto et al. 2007) and humans (de Roux et al. 2003), demonstrating the key role of the Kiss1/ Kiss $1 r$ system in the regulation of the HPG axis. In rodents, the Kiss 1 gene is mainly expressed in two hypothalamic nuclei: the anteroventral periventricular (AVPV) and arcuate (ARC) nuclei (Gottsch et al. 2004, Smith et al. 2005a, 2005b). It is translated into a 145 amino acid protein processed to generate one or several biologically active peptides named kisspeptins (Kp). Both human and rat Kp10 and Kp54 (Kp52 in the rat) share a 10 amino acid common C-terminus and bind to the KISS1 receptor with similar pharmacological 
characteristics (Kotani et al. 2001). Kp are very potent activators of the HPG axis since central administration of doses as low as $1 \mathrm{fmol}$ triggers the release of $\mathrm{LH}$ (Gottsch et al. 2004).

In the Syrian hamster, we have shown that Kiss1 mRNA levels in AVPV and ARC are significantly reduced under SD conditions and this effect is mediated by melatonin (Ansel et al. 2010). Furthermore, chronic administration of $\mathrm{Kp}$ to SD hamsters via a central route reverses the inhibitory effect of melatonin by reactivating the HPG axis, pointing to Kp as a pivotal gatekeeper of seasonal reproduction (Revel et al. 2006a, Simonneaux et al. 2009). Since peripheral administration of $\mathrm{Kp}$ has been reported to activate the HPG axis as does central infusion (Thompson et al. 2004, Navarro et al. 2005, Mikkelsen et al. 2009), we investigated whether long-term i.p. administration of $\mathrm{Kp}$ can restore gonadal activity in SD photo-inhibited male hamsters and further analysed the sites of action of peripheral Kp.

\section{Results}

Experiment 1: effect of long-term peripheral administration of Kp54 on testicular activity of photo-inhibited male hamsters

To examine whether peripheral administration of human Kp54 could restore reproductive activity of photoinhibited hamsters, two types of long-term administration were tested. Chronic delivery (4 weeks) of Kp54 via s.c. mini-pumps failed to increase testes weight and plasma testosterone of male hamsters kept in SD. Twice daily Kp54 injections (twice $10 \mathrm{nmol} /$ hamster) for 5 weeks significantly increased testes weight more than twofold ( $P=0.001$; Fig. $1 \mathrm{~B}$ ) and tended to increase basal levels of testosterone ( $P=0.07$; Fig. $1 \mathrm{~B})$ compared with vehicle-injected hamsters.

\section{Experiment 2: effect of an acute peripheral adminis- tration of Kp54 on the HPG axis in the hamster}

To reveal the sites of action of peripheral Kp, we studied the expression of the immediate early gene FOS in the forebrain and the pituitary after a single Kp54 i.p. injection. Kp54 strongly increased FOS immunoreactivity in hamsters' anterior pituitary compared with vehicle-treated hamsters $(P=0.005$; Fig. $2 \mathrm{~A}$ and $\mathrm{B})$. Dual FOS and LHB/FSHB labelling of pituitaries from animals injected with Kp54 revealed that over $90 \%$ of FOS-positive cells were gonadotrophs (Fig. 2C). The activation of gonadotrophs was accompanied by a large release of testosterone $(P<0.001 ;$ Fig. 2D). Strikingly, the effect of acute peripheral injection of GNRH on pituitary FOS expression and testosterone production was qualitatively and quantitatively similar to those of Kp54 (Fig. 2B-D). This finding suggests that peripheral Kp may act via a release of GNRH. To test this hypothesis, the

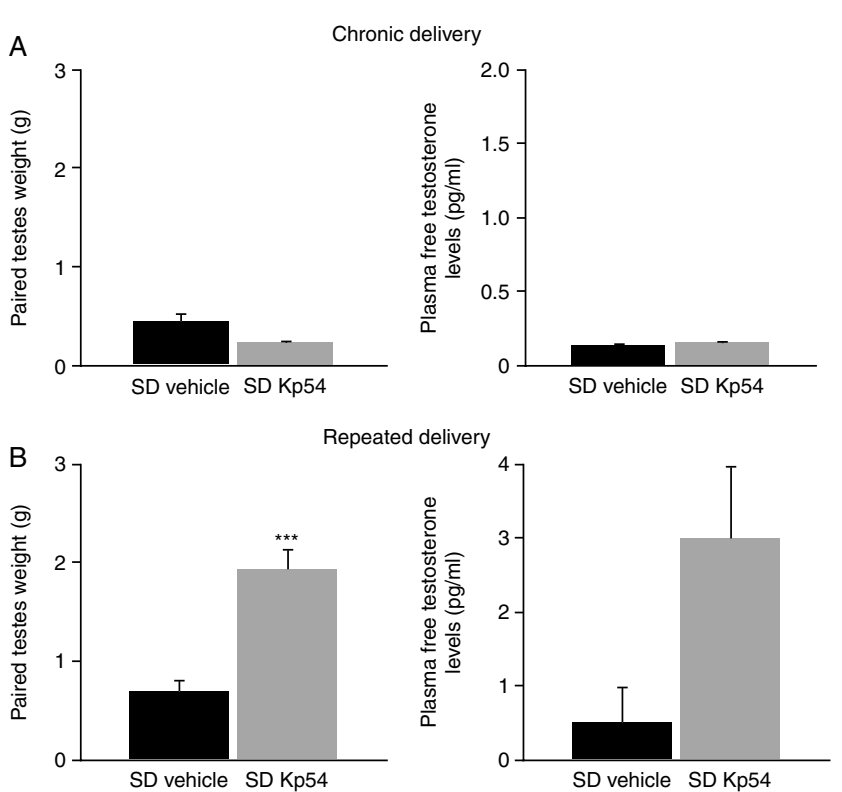

Figure 1 Effect of continuous or repeated long-term peripheral administration of $\mathrm{Kp} 54$ on testes weight and testosterone release of short day (SD)-adapted Syrian hamsters. (A) Mean value of paired testes weight (left panel) and concentration of free plasma testosterone (right panel) were measured in SD Syrian hamsters after 4 weeks of chronic s.c. administration of vehicle (Ringer) or Kp54 (10 nmol/hamster per day) via osmotic mini-pumps. Values are mean \pm s.E.M. $(n=5-6)$. (B) Mean value of paired testes weight (left panel) and concentration of plasma free testosterone (right panel) were measured in SD Syrian hamsters after 5 weeks of daily i.p. injections of vehicle (Ringer) or Kp54 (twice $10 \mathrm{nmol} /$ hamster). Values are mean \pm s.E.M. $(n=5-7)$,

*** $P<0.001$ compared with vehicle-injected hamsters (Student's $t$-test).

effect of Kp54 and GNRH was tested in the presence of a GNRH receptor antagonist, acyline.

Pretreatment with acyline not only completely blocked GNRH stimulatory effect, but also the effect of Kp54 ( $P=0.017$ and $P=0.028$, respectively; Fig. 3).

To determine the site of action of peripheral Kp54, we analysed the effect of peripherally administered Kp54 on FOS expression in GNRH neurons and downstream testosterone levels. Kp54 i.p. injection significantly induced FOS expression in about $60 \%$ of the GNRH neurons ( $P=0.0045$; Fig. $4 \mathrm{~A}$ and $\mathrm{B})$ and testosterone release $(P<0.001$; Fig. 4C) compared with vehicletreated counterparts.

\section{Experiment 3: effect of photoperiod on FOS expression in the hamster anterior pituitary}

To analyse the effect of photoperiod on GNRH- or Kp54-induced FOS expression in the pituitary, an i.p. injection of vehicle (Ringer; Braun Medical, Boulogne, France), GNRH or Kp54 was given to either LD- or SD-adapted hamsters. Both GNRH- and Kpinduced FOS expression in LD $(P<0.05$ and $P<0.001$, respectively; Fig. 5). While photoperiod did not affect 
A

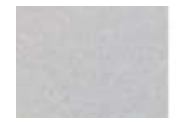

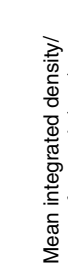

B
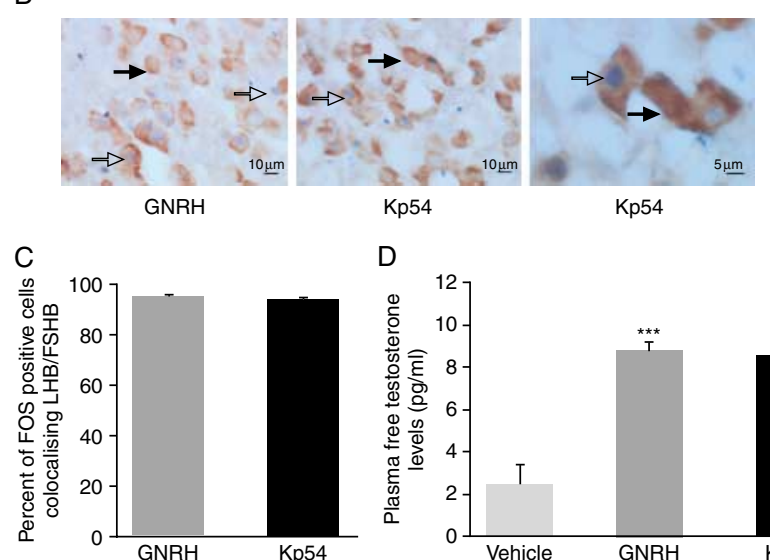

D

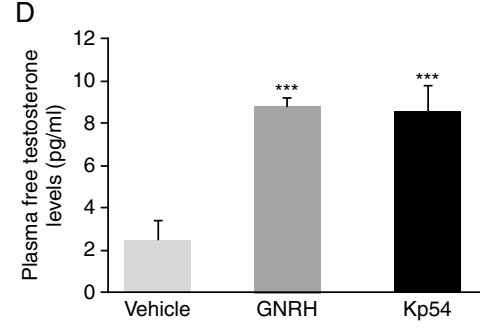

Figure 2 Effect of acute peripheral injection of Kp54 or GNRH on pituitary FOS expression and plasma testosterone level in the Syrian hamster. (A) Mean value of FOS immunoreactivity (arbitrary units, a.u.) in the pituitary of long day-adapted Syrian hamsters was analysed $2 \mathrm{~h}$ after an i.p. injection of vehicle (Ringer) or Kp54 (15 nmol/ hamster). The scale bar on pictures represents $50 \mu \mathrm{m}$. Values are mean \pm S.E.M. $(n=5),{ }^{* *} P<0.01$ compared with vehicle-injected hamsters (Student's $t$-test). (B) Phenotype of FOS-positive cells after GNRH or Kp54 i.p. injection in the pituitary of Syrian hamsters. Representative images of dual immunohistochemistry for FOS (blue, open arrows) and LHB/FSHB (brown, black arrows) in the anterior pituitary of long day-adapted Syrian hamsters $2 \mathrm{~h}$ after i.p. injection of GNRH (30 nmol/hamster) or Kp54 (15 nmol/hamster). (C) Proportion of FOS-positive cells co-localising LHB/FSHB in the anterior pituitary of Syrian hamsters $2 \mathrm{~h}$ after an i.p. injection of GNRH (30 nmol/hamster) or Kp54 (15 nmol/hamster). Values are mean \pm s.E.M. $(n=3)$.

(D) Concentration of free plasma testosterone $(\mathrm{pg} / \mathrm{ml}) 2 \mathrm{~h}$ after vehicle (Ringer), GNRH (30 nmol/hamster) or Kp54 (15 nmol/hamster) i.p. injection. Values are mean \pm s.E.M. $(n=5-6),{ }^{* * *} P<0.001$ compared with vehicle-injected hamsters (ANOVA followed by Tuckey's post hoc analysis).

GNRH-induced FOS expression, Kp54 induced a significantly larger expression of FOS in SD hamsters compared with LD hamsters $(P<0.01$; Fig. 5).

\section{Discussion}

Our study reports that long-term administration of Kp54 via a peripheral route reactivates the HPG axis of photoinhibited SD hamsters, providing the protocol is appropriately defined. Our study also indicates that peripheral Kp54 is acting by promoting GNRH release and downstream activation of pituitary gonadotrophs.
We observed that continuous s.c. administration of Kp54 to SD male hamsters using mini-pumps failed to reactivate the HPG axis as attested by low testes weight and low plasma testosterone levels. We previously reported that chronic central administration of Kp10 to SD male hamsters during 4 weeks is sufficient to restore LD-like testes weight and testosterone levels (Revel et al. 2006a). While centrally administered Kp could reach non-GNRH neurons targets, this might not be the case for peripherally given peptide. One can hypothesise that the activation of non-GNRH targets is required for the proper stimulation of the reproductive axis in a constant delivery protocol. The absence of effect of continuous s.c. administration of Kp54 is consistent with the finding that in SD Siberian hamsters, continuous peripheral administration of Kp10 failed to increase testes weight (Greives et al. 2008). Since the stability of Kp54 in the Alzet osmotic mini-pumps for several weeks was previously established (Revel et al. 2006a, Thompson et al. 2006), it appears unlikely that the lack of Kp54 effect in this protocol is only due to the degradation of the peptide in the pumps. Hence, one would speculate that the dose used was not appropriate; however, a prior study reported that continuous administration of a similar dose of Kp54 induced testicular degeneration in rats (Thompson et al. 2006). Therefore, we propose that the failure of continuous administration of Kp54 to activate testicular activity results from a downregulation/ desensitisation of the KISS1 receptor. Indeed, it has been reported that a preliminary continuous i.v. administration of Kp10 in male rhesus monkeys prevented the $\mathrm{LH}$ rise induced by a further bolus of Kp10 (Seminara et al. 2006, Ramaswamy et al. 2007). Moreover, continuous $\mathrm{Kp}$ exposure of mice mediobasal hypothalamus explants induced a sustained GNRH release for $4 \mathrm{~h}$ followed by a decrease, suggesting a desensitisation of the KISS1 receptor in the median eminence area (d'Anglemont de Tassigny et al. 2008). Alternatively, one might speculate that constant exposure to $\mathrm{Kp}$ induces a constant release of GNRH, which is known to desensitise pituitary GNRH receptors (Belchetz et al. 1978) and this could also explain the absence of effect of chronic Kp54 administration on gonadal activity in photo-inhibited hamsters. By contrast, we found that two daily injections of Kp54 for 5 weeks to SD-acclimated, sexually inactive, Syrian hamsters significantly increased testes weight, indicating a reactivation of the HPG axis despite the inhibitory photoperiod. The stimulatory effect of repeated versus continuous peripheral administration of Kp54 may indicate an absence of desensitisation/ downregulation of the KISS1 receptor or GNRH receptor using this protocol. This assumption is supported by the previous findings that intermittent infusions of Kp10 to juvenile agonadal male monkeys induce sustained GNRH-dependant LH pulsatile release (Plant et al. 2006) and that repeated i.v. administration of low doses of Kp10 to adult male rats increases $\mathrm{LH}$ levels 


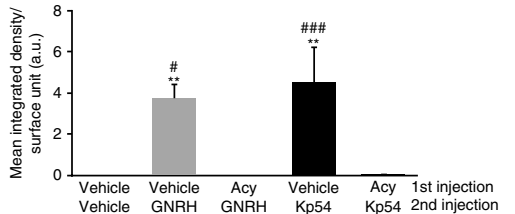

Figure 3 Effect of a GNRH antagonist on Kp-induced FOS expression in the anterior pituitary of the Syrian hamster. Mean value of FOS immunoreactivity (a.u.) in the pituitary of long day-adapted Syrian hamsters pretreated or not with acyline, a GNRH receptor antagonist (50 $\mu \mathrm{g} / \mathrm{hamster})$, then injected intraperitoneally with GNRH (30 nmol/ hamster) or Kp54 (15 nmol/hamster) $2 \mathrm{~h}$ before killing. Values are mean \pm s.E.M. $(n=3-6), * * P<0.01$ compared with vehicle-injected hamsters (ANOVA followed by Tuckey's post hoc analysis); ${ }^{\#} P<0.05$,

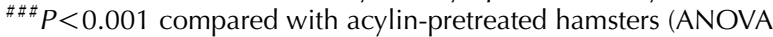
followed by Tuckey's post hoc analysis).

without evidence of desensitisation (Tovar et al. 2006). However, further experiments are required to clearly establish the existence of this phenomenon and its mechanisms in the Syrian hamster.

Another study reported that one daily i.p. injection of Kp10 failed to reactivate the HPG axis in photo-inhibited Siberian hamsters (Greives et al. 2008). Discrepancies between this study and ours can be explained by the form of the peptide used, the frequency of peripheral administration and the animal model chosen. First, longer forms of the human peptide tend to act in a prolonged manner compared with shorter forms (Mikkelsen et al. 2009). Secondly, one daily injection might not be enough to induce a sustained activation of the HPG axis. Indeed, so far only a frequency of two daily peripheral bolus of Kp10 over $60 \mathrm{~h}$ caused ovulation in seasonally acyclic ewes (Caraty et al. 2007), underlining the importance of the frequency of administration. Thirdly, Syrian and Siberian hamsters display different photoperiodic responses (Bartness et al. 1993) and Kiss 1 mRNA regulation by photoperiod is opposite in the arcuate nucleus of the two species (Greives et al. 2007, Simonneaux et al. 2009, Ansel et al. 2010). These observations suggest there exist important differences regarding the effect and physiological roles of $\mathrm{Kp}$ in mediating photoperiodic control of the reproductive axis between Siberian and Syrian hamsters.

To elucidate the target site(s) of peripheral Kp54, we examined FOS expression as a marker of cellular activation in the brain and pituitary. Peripheral Kp54 strongly induced labelling experiment showed that Kp-FOS expression in the anterior pituitary, an effect followed by the downstream increase in levels of circulating testosterone reflecting increased $\mathrm{LH}$ secretion. The dual-induced FOS expression in the anterior pituitary is restricted to gonadotrophs. A direct effect of Kp on the pituitary is still a matter of debate. In cultured pituitary cells from peripubertal rats (Gutierrez-Pascual et al. 2007) or glands from pubertal rats (Navarro et al. 2005) application of $10 \mathrm{nM}$ Kp10 increased $\mathrm{LH}$ release but did not affect FSH levels.
However, on cultured anterior pituitaries (Thompson et al. 2004) or dissociated cells of anterior pituitaries (Matsui et al. 2004) from adult rats exogenous Kp10 failed to increase LH or FSH even at doses as high as $1 \mu \mathrm{M}$. In the adult Syrian hamster, the effect of Kp54 on FOS immunoreactivity in the anterior pituitary was completely blocked by acyline, a GNRH antagonist. Thus, peripheral Kp54 activates the pituitary in a GNRH-dependant manner. Our results are in line with prior studies in sheep showing that peripheral Kp-induced GNRH release in cerebrospinal fluid (Caraty et al. 2007) but failed to induce LH release in hypothalamopituitary disconnected animals (Smith et al. 2008), and that in rodents, acyline prevented $\mathrm{Kp}$-induced LH release (Gottsch et al. 2004, Irwig et al. 2004, Mikkelsen et al. 2009). These observations indicate that peripheral Kp54 activates the pituitary gonadotrophs via the release of GNRH and exclude a direct effect of the peptide on the pituitary. However, the precise site of action of
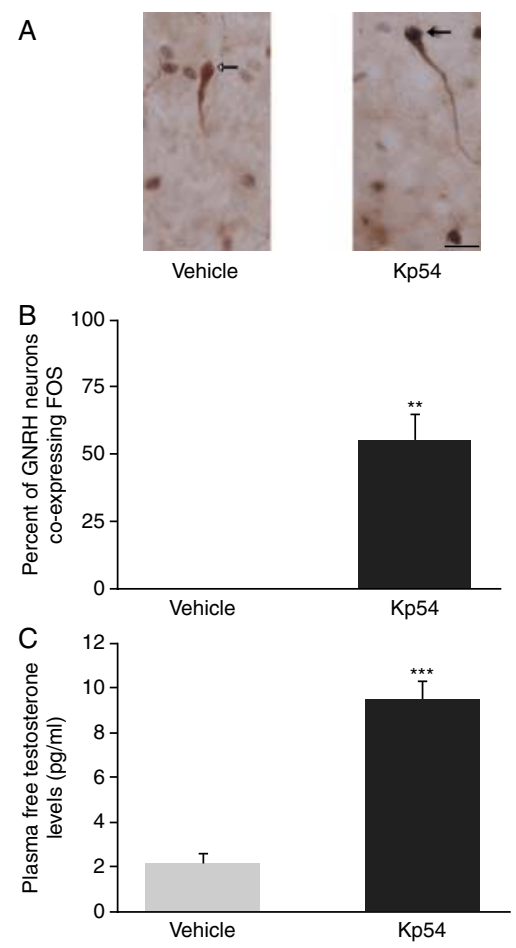

Figure 4 Effect of peripheral Kp54 injection on FOS expression in GNRH neurons and subsequent testosterone in the same animals. (A) The images show FOS immunoreactivity in GNRH neurons of Syrian hamsters kept in long days and injected peripherally with vehicle (Ringer, left panel) or Kp54 (15 nmol/hamster, right panel) $2 \mathrm{~h}$ before killing. An open arrow indicates a FOS-negative GNRH neuron while a black arrow points to cells expressing both GNRH and FOS. The scale bar represents $20 \mu \mathrm{m}$. (B) Percentage of GNRH neurons expressing FOS in the anterior hypothalamus of Syrian hamsters $2 \mathrm{~h}$ after an i.p. injection of vehicle or Kp54. Values are mean \pm S.E.M. $(n=6)$,

${ }^{* *} P<0.001$ compared with vehicle-treated hamsters (Student's $t$-test). (C) Concentration of free plasma testosterone $(\mathrm{pg} / \mathrm{ml}) 2 \mathrm{~h}$ after vehicle, or Kp54 i.p. injection. Values are mean \pm s.E.M. $(n=6), * * * P<0.001$ compared with vehicle-injected hamsters (Student's $t$-test). 


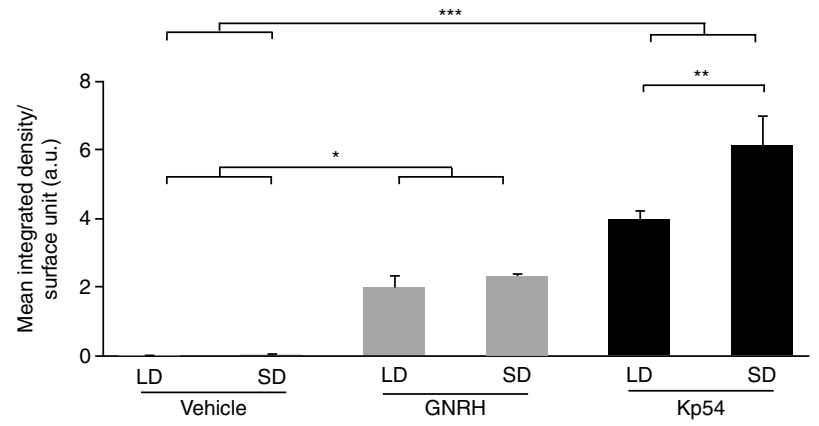

Figure 5 Effect of photoperiod on GNRH or Kp54-induced FOS expression in the Syrian hamster pituitary. Mean value of FOS immunoreactivity (arbitrary unit, a.u.) in the anterior pituitary of Syrian hamsters kept in long days (LD) or short days (SD) injected intraperitoneally with vehicle (Ringer), GNRH (30 nmol/hamster) or Kp54 (15 nmol/hamster) $2 \mathrm{~h}$ before killing. Values are mean \pm s.E.M. $(n=5-6), * P<0.05, * * P<0.01$ and ${ }^{* * *} P<0.001$ when compared with Kp54-injected LD hamsters (two-way ANOVA followed by Bonferroni's post hoc analysis).

peripheral Kp on GNRH neurons remains unknown. We found that peripheral Kp54 increased FOS in GNRH neurons. In a prior study in mice, we showed that peripheral mouse Kp10 failed to induce FOS expression in GNRH cell bodies (Mikkelsen et al. 2009). The reason for this difference could be a matter of peptide sequence. Our new findings confirm a number of other studies showing that peripheral Kp54 is acting upstream of the pituitary, on GNRH neurons. Peripheral Kp could act on GNRH nerve terminals of the median eminence to induce GNRH release as suggested by the presence of a few $\mathrm{Kp}$ immunoreactive fibres in the external layer of the median eminence of the Syrian hamster (L Ansel, D Streicher, J Bartzen, JD Mikkelson \& V Simonneaux 2009, unpublished observations) and the female rat (Desroziers et al. 2010). Furthermore, the ability of Kp to induce GNRH release from mice mediobasal hypothalamus explants despite tetrodotoxin pretreatment (d'Anglemont de Tassigny et al. 2008) strengthens this hypothesis. However, the possibility that peripheral Kp crosses the blood-brain barrier requires experiments to be substantiated.

Because Syrian hamsters display marked photoperiodic variations in both Kiss1 and Kp expression with lower levels in SD (Revel et al. 2006a, Simonneaux et al. 2009, Ansel et al. 2010), we investigated whether gonadotrophs responsiveness to Kp or GNRH depends on photoperiod. An acute injection of Kp54 increased FOS immunoreactivity in the pituitary of SD than of LD-adapted animals. The increased FOS immunoreactivity in SD animals is not due to a photoperiodic change in the anterior pituitary's responsiveness to GNRH since there was no effect of photoperiod on GNRH-induced FOS expression. Insufficient dose of GNRH cannot account for the lack of photoperiodic difference in GNRH effect on FOS expression in our study since a dose as low as $0.1 \mathrm{nmol}$ of $\mathrm{GNRH}$ given subcutaneously induces a massive LH release in Syrian hamsters (Pickard \& Silverman 1979). Moreover, previous studies reported no photoperiodic difference of pituitary response to exogenous GNRH (Pickard \& Silverman 1979). Therefore, Kp54 sensitivity to photoperiod probably occurs at the level of the GNRH neurons. One might speculate that low levels of $\mathrm{Kp}$ in SD hamsters (Revel et al. 2006a) could upregulate/ resensitise KISS1 receptor at the GNRH neurons. Indeed, in fasting prepubertal rats, a condition where Kiss 1 mRNA is decreased and Kiss1r mRNA is increased (Castellano et al. 2005), Kp10 is more potent to induce $\mathrm{LH}$ release (Castellano et al. 2005), indicating a higher sensitivity of the HPG axis in undernutrition. However, a feedback effect of testosterone, a direct effect of photoperiod/melatonin on GNRH neurons sensitivity to $\mathrm{Kp}$ or an increase in the releasable pool of GNRH cannot be excluded.

In conclusion, our data demonstrate that exogenous peripheral Kp54 reactivates a photo-inhibited HPG axis by stimulating GNRH release and this sensitivity to Kp54 is photoperiod-dependant. Taken together, our data confirm the key role played by Kp in the seasonal control of reproduction in the Syrian hamster and demonstrate that peripheral Kp54 is also effective under certain conditions. In light of the existing litterature, our results also suggest that long and short forms of $\mathrm{Kp}$ are not interchangeable and that Siberian and Syrian hamsters display considerable differences in the effects and physiological roles of Kp on the reproductive axis.

\section{Materials and Methods}

\section{Animals}

Male Syrian hamsters (Mesocricetus auratus) weighing 100-180 g were raised in our animal facilities (INCI, Strasbourg, France) with food and water ad libitum, under controlled temperature $\left(22 \pm 1{ }^{\circ} \mathrm{C}\right)$ and long photoperiod (LD; $14 \mathrm{~h}$ light (200 lux):10 h darkness (2 lux, dim red light) cycle with lights on at $0600 \mathrm{~h}$ ). When required, hamsters were exposed to short photoperiod (SD; $10 \mathrm{~h}$ light:14 $\mathrm{h}$ darkness cycle with lights on at $1000 \mathrm{~h}$ ) for 10 weeks. All experiments were conducted in accordance with the French National Law (licence $n^{\circ}$ 67-32) implementing the European Communities Council Directives of 24 November 1986 (86/609/EEC).

\section{Peptide and reagents}

Human Kp54 was selected to investigate the effect of peripheral $\mathrm{Kp}$ on the gonadotropic axis because it exerts a long-lasting effect on the HPG axis compared with Kp10 (Mikkelsen et al. 2009). It was synthetised by GenScript (Piscataway, NJ, USA). GNRH was purchased from Sigma and acyline, a selective GNRH antagonist (Herbst 2003), was kindly provided by Drs John Amory and William J Bremner from the University of Washington, Seattle, USA. 


\section{Experimental designs}

Experimental design 1: effect of long-term peripheral administration of Kp54 on testicular activity of photo-inhibited male hamsters

To examine whether peripheral administration of Kp54 could restore reproductive activity of photo-inhibited hamsters, two types of long-term administration were tested. Hamsters ( $n=6-7$ /group) were transferred to SD for 10 weeks, after which testicular regression was verified by scrotal palpation. In the first protocol, s.c. chronic administration was tested with osmotic mini-pumps (Alzet, Charles River, Arbresle, France; model 2004, 4-week treatment) filled with either vehicle (Ringer) or Kp54 $(140 \mu \mathrm{M}$, i.e. $10 \mathrm{nmol} / \mathrm{hamster}$ per day) delivered at a rate of $2.5 \mu \mathrm{l} / \mathrm{h}$ over a period of 28 days. The dose of Kp54 was chosen according to previous studies in rats (Thompson et al. 2006). The hamsters were anaesthetised with $3 \%$ isoflurane and a small incision of the skin was made in the interscapular region. A haemostat was used to create a pocket into which the pump was inserted with the flow moderator facing away from the incision. Xylocain was administered in the wound before the skin was sutured with wound clips. In the second protocol, hamsters were intraperitoneally injected (10 nmol/hamster) twice daily ( $1 \mathrm{~h}$ after lights on and when lights off) with either vehicle (Ringer) or Kp54 (100 $\mu \mathrm{M})$. The hamsters were kept in SD for the 4 or 5 weeks (first and second protocol, respectively, ) of Ringer or Kp54 administration. In twice daily intraperitoneally injected hamsters, 4 weeks of treatment increased testes size as examined by scrotal palpation. Injections were performed for one more week to maximise Kp54 effect. Hamsters' body weight was measured at the beginning and at the end of the period of Kp54 chronic administration. At the end of the experiments, the hamsters were killed by decapitation after deep isoflurane anaesthesia (AErrane; Baxter, Maurepas, France). Trunk blood was collected in heparinised tubes. The plasma was separated and stored at $-20{ }^{\circ} \mathrm{C}$ until testosterone assay. The testes were immediately dissected and weighed.

Experimental design 2: effect of an acute peripheral administration of Kp54 on the HPG axis in the hamster

To identify Kp sites of action, we examined the effect of peripheral administration of Kp54 on FOS expression in GNRH neurons and the pituitary. LD-acclimated hamsters ( $n=5$ /group) were intraperitoneally $(100 \mu \mathrm{l} /$ hamster $)$ injected with a vehicle solution (Ringer) or $150 \mu \mathrm{M} \mathrm{Kp54}$ solution (15 nmol/hamster). Two hours after injection, hamsters were deeply anaesthetised with isoflurane vapours and perfused transcardially with $4 \%$ formaldehyde in $0.1 \mathrm{M}$ phosphate buffer $\mathrm{pH}$ 7.4. The rostral area of the forebrain known to contain GNRH neurons and the entire pituitary tissue (both anterior and posterior lobes) were sectioned and the expression of FOS was analysed by semi-quantitative immunohistochemistry.

Dual labellings were performed to phenotype FOS responsive cells in the pituitary and forebrain. The pituitaries of three GNRH-injected and three Kp54-injected hamsters were processed for dual FOS and LHB/FSHB immunohistochemistry. Three sections per pituitary were processed and for each section, three different areas were analysed.
To determine whether the effect of Kp54 on the pituitary is direct or mediated via GNRH, five groups of LD-acclimated hamsters ( $n=4-6 /$ group) were intraperitoneally injected (100 $\mu \mathrm{l} /$ hamster) first with either vehicle (Ringer) or $50 \mu \mathrm{g}$ of the GNRH receptor antagonist acyline, then, $1 \mathrm{~h}$ later, with vehicle or $300 \mu \mathrm{M}$ GNRH or $150 \mu \mathrm{M}$ Kp54. Two hours after the last injection, animals were killed as described previously and pituitary tissues were examined for FOS expression. Moreover, to find out if pituitary cell activation is correlated to downstream activation of the HPG axis, blood was taken by cardiac puncture. The plasma was extracted, stored at $-20{ }^{\circ} \mathrm{C}$ and processed for testosterone assay. Testosterone was preferred to $\mathrm{LH}$ to assess the downstream activation of the HPG axis because peripheral $\mathrm{Kp}$ effect on $\mathrm{LH}$ release is no longer detectable $60 \mathrm{~min}$ after the injection (Navarro et al. 2005) whereas Kp54 exerts a long-lasting effect on testosterone secretion in the rat (Mikkelsen et al. 2009).

\section{Experimental design 3: effect of photoperiod on FOS expression in the hamster anterior pituitary}

Hamsters were kept in LD or SD for 10 weeks (three groups per photoperiod, $n=6 /$ group). For each photoperiod, groups of hamsters received a single i.p. injection of either vehicle (Ringer), $300 \mu \mathrm{M}$ GNRH or $150 \mu \mathrm{M}$ Kp54. Two hours after the injection, the hamsters were deeply anaesthetised with pentobarbital $(5 \mathrm{ml} / \mathrm{kg}$ ) and perfused transcardially with $4 \%$ formaldehyde in 0.1 M PBS pH 7.4. The fixed testes were dissected and weighed to examine for photoperiodic regression. The pituitaries were removed and processed for FOS immunohistochemistry.

\section{Immunohistochemistry}

After perfusion of $4 \%$ formaldehyde, brain with the pituitary attached was immediately removed from the skull, postfixed for $24 \mathrm{~h}$ at $4{ }^{\circ} \mathrm{C}$ in the same fixative, rinsed overnight in PBS, dehydrated and embedded in polyethylene glycol as described by Klosen et al. (1993). Microtome sections (12 $\mu \mathrm{m}$ thick) were cut and processed (one every $120 \mu \mathrm{m}$ ) for immunohistochemistry. For FOS detection, non-specific binding sites were saturated for $1 \mathrm{~h}$ with $3 \%$ dry skimmed milk. Primary antiFOS rabbit polyclonal antibody $(1: 2000$, Santa Cruz Biotechnologies, Santa Cruz, CA, USA) was applied overnight. This antibody is unlikely to detect Fos-related antigens because it was raised against the $\mathrm{N}$-terminus of the protein, region showing little similarity with Fos-related antigens. The sections were then incubated for $1 \mathrm{~h}$ with a secondary biotinylated donkey anti-rabbit antibody (1:2000, Jackson Immunoresearch Laboratories, West Grove, PA, USA) followed by a $1 \mathrm{~h}$ incubation with streptavidin-peroxidase (1:2000, Roche). Peroxidase activity was detected using 3,3'-diaminobenzidine (Sigma) as a chromogen. The slides were then dehydrated and mounted with Eukitt.

For the quantification of FOS immunohistochemistry, photomicrographs of pituitaries were taken with a Leica DMRB microscope (Leica Microsystems, Rueil-Malmaison, France) equipped with an Olympus DP50 digital camera (Olympus France, Rungis, France). All parameters of the microscope and 
the camera software (Viewfinder Lite, Olympus) were standardised. Photomicrographs were taken with a $5 \times$ objective and quantified with Imagel software (Rasband, W.S., US National Institutes of Health, Bethesda MD, USA). The quantification method used was adapted with minor modifications from Salingre et al. (2009). Briefly, pictures were thresholded according to the intensity of the background and the same threshold was applied for each individual experiment. A particle analysis was performed on the pituitary and particles whose diameter was inferior to 30 pixels were excluded. The sum of the integrated density of each immunoreactive particle (i.e. FOS-positive cell) was calculated and divided by the total area quantified to obtain a mean integrated density per surface unit taking into account both the number of immunoreactive particles and the intensity of the staining.

\section{FOS-LHB/FSHB dual immunohistochemistry in pituitary tissue}

For dual FOS and LHB/FSHB immunohistochemistry, endogenous alkaline phosphatase was inhibited with $15 \%$ acetic acid for $5 \mathrm{~min}$. The sections were first processed for FOS immunohistochemistry as described previously except for the enzyme label (streptavidin-alkaline phosphatase, 1:2000, Roche). The enzymatic activity was detected for 40 min using Naphtol AS MX phosphate as substrate and Fast Blue BB as a chromogen. The FOS and the biotinylated donkey anti-rabbit antibodies were then eluted with $100 \mathrm{mM}$ glycine and $0.3 \%$ Triton X-100 for twice $15 \mathrm{~min}$. Gonadotrophs were labelled with a mix of anti-LHB and anti-FSHB antibodies (LHB: 1:60 000 rabbit polyclonal antibody; FSHB: 1:40 000 rabbit polyclonal antibody, both from National Hormone and Peptide Program). LHB and FSHB presence was detected with peroxidase and 3,3'-diaminobenzidine as described earlier.

For FOS and $\mathrm{LHB} / \mathrm{FSHB}$ dual staining, the total number of blue positive nuclei and brown LHB/FSHB-FOS-positive cells was counted manually by an observer unaware of the treatment of individual animals. The proportion of gonadotrophs expressing FOS and the proportion of FOS-positive cells expressing LHB/FSHB were calculated for each animal.

\section{FOS-GNRH dual immunohistochemistry}

After fixation, brain sections were processed as described previously with minor modifications (Mikkelsen et al. 2009). Briefly, sections were incubated in a rabbit serum against FOS (1:12 000 (Mikkelsen et al. 1998)), immunoreacted with biotinylated donkey anti-rabbit serum (1:1000, cat\#711-066152, Jackson Labs) and reaction product visualised using a nickel-enhanced diaminobenzidine method resulting in a black staining of the FOS-labelled nuclei. After several PBS washes, the FOS-stained sections were incubated with a rabbit antiserum against GNRH (1:4000, cat\#H-040-02; Phoenix Pharmaceuticals, Burlingame, CA, USA) stained with the same avidin-biotin method described earlier, but the reaction product was detected using 3,3'-diaminobenzidine as a chromogen. Finally, the sections were mounted on gelatinised glass slides, dried and coverslipped in Depex.

For quantification, all GNRH-immunoreactive neurons were counted by an observer unaware of the treatment group. Double-labelled neurons characterised by a blackstained nucleus within a brown bipolar neuron were counted, and for each animal the percentage of observed GNRHimmunoreactive neurons that co-expressed nuclear FOS staining were calculated.

\section{Testosterone assay}

Free testosterone levels were measured using a direct RIA kit (DPC coat-a-count RIA method; Siemens Medical Solutions, Mölndal, Sweden) as described previously (Mikkelsen et al. 2009). The kit analytical sensitivity is of $15 \mathrm{pg} / \mathrm{ml}$. The coefficients of variation are of $18.3,8.5$ and $8.0 \%$ for mean testosterone values of $1.2,8.9$ and $20 \mathrm{pg} / \mathrm{ml}$ respectively.

\section{Statistical analysis}

Student's t-test or one-way ANOVA was carried out followed by Tuckey's multicomparisons. For experiment 3, a two-way ANOVA was performed followed by Bonferroni's multicomparisons. Two-tailed $P$ values are expressed as $* P<0.05$, $* * P<0.01$ and $* * * P<0.001$.

\section{Declaration of interest}

The authors declare that there is no conflict of interest that could be perceived as prejudicing the impartiality of the research project reported.

\section{Funding}

This work was supported by the 'Region Alsace', the French 'Agence Nationale de la Recherche' (grant number BLAN-070056), the Danish Medical Research Council, the NOVO Nordisk Foundation, the Sawmill owner Jeppe Juhl and wife Ovita Juhls' Foundation and the European Doctoral College of Strasbourg.

\section{Acknowledgements}

The authors thank Dr F Parlow and the National Hormone and Pituitary Program of the NIDDK for the gift of the anti-hormone antibodies, as well as Dr A Salingre for his precious help with ImageJ software.

\section{References}

d'Anglemont de Tassigny X, Fagg LA, Dixon JP, Day K, Leitch HG, Hendrick AG, Zahn D, Franceschini I, Caraty A, Carlton MB et al. 2007 Hypogonadotropic hypogonadism in mice lacking a functional Kiss1 gene. PNAS 104 10714-10719. (doi:10.1073/pnas.0704114104)

d'Anglemont de Tassigny X, Fagg LA, Carlton MB \& Colledge WH 2008 Kisspeptin can stimulate gonadotropin-releasing hormone $(\mathrm{GnRH})$ release by a direct action at $\mathrm{GnRH}$ nerve terminals. Endocrinology 149 3926-3932. (doi:10.1210/en.2007-1487)

Ansel L, Bolborea M, Bentsen AH, Klosen P, Mikkelsen JD \& Simonneaux V 2010 Differential regulation of kiss1 expression by melatonin and gonadal hormones in male and female Syrian hamsters. Journal of Biological Rhythms 25 81-91. (doi:10.1177/0748730410361918) 
Bartness TJ, Powers JB, Hastings MH, Bittman EL \& Goldman BD 1993 The timed infusion paradigm for melatonin delivery: what has it taught us about the melatonin signal, its reception, and the photoperiodic control of seasonal responses? Journal of Pineal Research 15 161-190. (doi:10. 1111/j.1600-079X.1993.tb00903.x)

Belchetz PE, Plant TM, Nakai Y, Keogh EJ \& Knobil E 1978 Hypophysial responses to continuous and intermittent delivery of hypothalamic gonadotropin-releasing hormone. Science 202 631-633. (doi:10.1126/ science.100883)

Caraty A, Smith JT, Lomet D, Ben Said S, Morrissey A, Cognie J, Doughton B, Baril G, Briant C \& Clarke IJ 2007 Kisspeptin synchronizes preovulatory surges in cyclical ewes and causes ovulation in seasonally acyclic ewes. Endocrinology 148 5258-5267. (doi:10.1210/en.20070554)

Castellano JM, Navarro VM, Fernandez-Fernandez $R$, Nogueiras $R$, Tovar S, Roa J, Vazquez MJ, Vigo E, Casanueva FF, Aguilar E et al. 2005 Changes in hypothalamic KiSS-1 system and restoration of pubertal activation of the reproductive axis by kisspeptin in undernutrition. Endocrinology 146 3917-3925. (doi:10.1210/en.2005-0337)

Desroziers E, Mikkelsen J, Simonneaux V, Keller M, Tillet Y, Caraty A \& Franceschini I 2010 Mapping of kisspeptin fibres in the brain of the pro-oestrous rat. Journal of Neuroendocrinology 22 1101-1112. (doi:10. 1111/j.1365-2826.2010.02053.x)

Funes S, Hedrick JA, Vassileva G, Markowitz L, Abbondanzo S, Golovko A, Yang S, Monsma FJ \& Gustafson EL 2003 The KiSS-1 receptor GPR54 is essential for the development of the murine reproductive system. Biochemical and Biophysical Research Communications 312 1357-1363. (doi:10.1016/j.bbrc.2003.11.066)

Goldman BD 2001 Mammalian photoperiodic system: formal properties and neuroendocrine mechanisms of photoperiodic time measurement. Journal of Biological Rhythms 16 283-301. (doi:10.1177/07487 3001129001980)

Gottsch ML, Cunningham MJ, Smith JT, Popa SM, Acohido BV, Crowley WF, Seminara S, Clifton DK \& Steiner RA 2004 A role for kisspeptins in the regulation of gonadotropin secretion in the mouse. Endocrinology 145 4073-4077. (doi:10.1210/en.2004-0431)

Greives TJ, Mason AO, Scotti MA, Levine J, Ketterson ED, Kriegsfeld LJ \& Demas GE 2007 Environmental control of kisspeptin: implications for seasonal reproduction. Endocrinology 148 1158-1166. (doi:10.1210/en. 2006-1249)

Greives TJ, Kriegsfeld LJ \& Demas GE 2008 Exogenous kisspeptin does not alter photoperiod-induced gonadal regression in Siberian hamsters (Phodopus sungorus). General and Comparative Endocrinology 156 552-558. (doi:10.1016/j.ygcen.2008.02.017)

Gutierrez-Pascual E, Martinez-Fuentes AJ, Pinilla L, Tena-Sempere M, Malagon MM \& Castano JP 2007 Direct pituitary effects of kisspeptin: activation of gonadotrophs and somatotrophs and stimulation of luteinising hormone and growth hormone secretion. Journal of Neuroendocrinology 19 521-530. (doi:10.1111/j.1365-2826.2007. 01558.x)

Herbst KL 2003 Gonadotropin-releasing hormone antagonists. Current Opinion in Pharmacology 3 660-666. (doi:10.1016/j.coph.2003. 06.009)

Irwig MS, Fraley GS, Smith JT, Acohido BV, Popa SM, Cunningham MJ, Gottsch ML, Clifton DK \& Steiner RA 2004 Kisspeptin activation of gonadotropin releasing hormone neurons and regulation of KiSS-1 mRNA in the male rat. Neuroendocrinology 80 264-272. (doi:10.1159/ 000083140)

Klosen P, Maessen X \& van den Bosch de Aguilar P 1993 PEG embedding for immunocytochemistry: application to the analysis of immunoreactivity loss during histological processing. Journal of Histochemistry and Cytochemistry 41 455-463. (doi:10.1177/41.3.8429209)

Kotani M, Detheux M, Vandenbogaerde A, Communi D, Vanderwinden JM, Le Poul E, Brezillon S, Tyldesley R, SuarezHuerta N, Vandeput F et al. 2001 The metastasis suppressor gene KiSS-1 encodes kisspeptins, the natural ligands of the orphan G proteincoupled receptor GPR54. Journal of Biological Chemistry 276 34631-34636. (doi:10.1074/jbc.M104847200)

Lapatto R, Pallais JC, Zhang D, Chan YM, Mahan A, Cerrato F, Le WW, Hoffman GE \& Seminara SB 2007 Kiss1 - / - mice exhibit more variable hypogonadism than Gpr54-/- mice. Endocrinology 148 4927-4936. (doi:10.1210/en.2007-0078)
Matsui H, Takatsu Y, Kumano S, Matsumoto H \& Ohtaki T 2004 Peripheral administration of metastin induces marked gonadotropin release and ovulation in the rat. Biochemical and Biophysical Research Communications 320 383-388. (doi:10.1016/j.bbrc.2004.05.185)

Mikkelsen JD, Vrang N \& Mrosovsky N 1998 Expression of Fos in the circadian system following nonphotic stimulation. Brain Research Bulletin 47 367-376. (doi:10.1016/S0361-9230(98)00121-X)

Mikkelsen JD, Bentsen AH, Ansel L, Simonneaux V \& Juul A 2009 Comparison of the effects of peripherally administered kisspeptins. Regulatory Peptides 152 95-100. (doi:10.1016/j.regpep.2008.10.001)

Navarro VM, Castellano JM, Fernandez-Fernandez R, Tovar S, Roa J, Mayen A, Nogueiras R, Vazquez MJ, Barreiro ML, Magni P et al. 2005 Characterization of the potent luteinizing hormone-releasing activity of KiSS-1 peptide, the natural ligand of GPR54. Endocrinology 146 156-163. (doi:10.1210/en.2004-0836)

Pickard GE \& Silverman AJ 1979 Effects of photoperiod on hypothalamic luteinizing hormone releasing hormone in the male hamster. Journal of Endocrinology 83 421-428. (doi:10.1677/joe.0.0830421)

Plant TM, Ramaswamy S \& Dipietro MJ 2006 Repetitive activation of hypothalamic G protein-coupled receptor 54 with intravenous pulses of kisspeptin in the juvenile monkey (Macaca mulatta) elicits a sustained train of gonadotropin-releasing hormone discharges. Endocrinology 147 1007-1013. (doi:10.1210/en.2005-1261)

Ramaswamy S, Seminara SB, Pohl CR, DiPietro MJ, Crowley WF Jr \& Plant TM 2007 Effect of continuous intravenous administration of human metastin 45-54 on the neuroendocrine activity of the hypothalamic-pituitary-testicular axis in the adult male rhesus monkey (Macaca mulatta). Endocrinology 148 3364-3370. (doi:10.1210/en. 2007-0207)

Reiter RJ 1980 The pineal and its hormones in the control of reproduction in mammals. Endocrine Reviews 1 109-131. (doi:10.1210/edrv-12-109)

Revel FG, Saboureau M, Masson-Pevet M, Pevet P, Mikkelsen JD \& Simonneaux V 2006a Kisspeptin mediates the photoperiodic control of reproduction in hamsters. Current Biology 16 1730-1735. (doi:10.1016/ j.cub.2006.07.025)

Revel FG, Saboureau M, Pevet P, Mikkelsen JD \& Simonneaux V $2006 b$ Melatonin regulates type 2 deiodinase gene expression in the Syrian hamster. Endocrinology 147 4680-4687. (doi:10.1210/en.2006-0606)

Revel FG, Saboureau M, Pevet P, Simonneaux V \& Mikkelsen JD 2008 RFamide-related peptide gene is a melatonin-driven photoperiodic gene. Endocrinology 149 902-912. (doi:10.1210/en.2007-0848)

de Roux N, Genin E, Carel JC, Matsuda F, Chaussain JL \& Milgrom E 2003 Hypogonadotropic hypogonadism due to loss of function of the KiSS1derived peptide receptor GPR54. PNAS 100 10972-10976. (doi:10. 1073/pnas.1834399100)

Salingre A, Klosen P, Pévet P \& Simonneaux V 2009 Daytime gating in the Syrian hamster pineal gland. Journal of Neuroendocrinology 21 760-769. (doi:10.1111/j.1365-2826.2009.01897.x)

Seminara SB, Messager S, Chatzidaki EE, Thresher RR, Acierno JS Jr, Shagoury JK, Bo-Abbas Y, Kuohung W, Schwinof KM, Hendrick AG et al. 2003 The GPR54 gene as a regulator of puberty. New England Journal of Medicine 349 1614-1627. (doi:10.1056/NEJMoa035322)

Seminara SB, Dipietro MJ, Ramaswamy S, Crowley WF Jr \& Plant TM 2006 Continuous human metastin 45-54 infusion desensitizes $G$ proteincoupled receptor 54-induced gonadotropin-releasing hormone release monitored indirectly in the juvenile male Rhesus monkey (Macaca mulatta): a finding with therapeutic implications. Endocrinology 147 2122-2126. (doi:10.1210/en.2005-1550)

Simonneaux V, Ansel L, Revel FG, Klosen P, Pevet P \& Mikkelsen JD 2009 Kisspeptin and the seasonal control of reproduction in hamsters. Peptides 30 146-153. (doi:10.1016/j.peptides.2008.06.006)

Smith JT, Cunningham MJ, Rissman EF, Clifton DK \& Steiner RA 2005a Regulation of Kiss1 gene expression in the brain of the female mouse. Endocrinology 146 3686-3692. (doi:10.1210/en.2005-0488)

Smith JT, Dungan HM, Stoll EA, Gottsch ML, Braun RE, Eacker SM, Clifton DK \& Steiner RA 2005b Differential regulation of KiSS-1 mRNA expression by sex steroids in the brain of the male mouse. Endocrinology 146 2976-2984. (doi:10.1210/en.2005-0323)

Smith JT, Rao A, Pereira A, Caraty A, Millar RP \& Clarke IJ 2008 Kisspeptin is present in ovine hypophysial portal blood but does not increase during 
the preovulatory luteinizing hormone surge: evidence that gonadotropes are not direct targets of kisspeptin in vivo. Endocrinology 149 1951-1959. (doi:10.1210/en.2007-1425)

Thompson EL, Patterson M, Murphy KG, Smith KL, Dhillo WS, Todd JF, Ghatei MA \& Bloom SR 2004 Central and peripheral administration of kisspeptin-10 stimulates the hypothalamic-pituitary-gonadal axis. Journal of Neuroendocrinology 16 850-858. (doi:10.1111/j.1365-2826. 2004.01240.x)

Thompson EL, Murphy KG, Patterson M, Bewick GA, Stamp GW, Curtis AE, Cooke JH, Jethwa PH, Todd JF, Ghatei MA et al. 2006 Chronic subcutaneous administration of kisspeptin-54 causes testicular degeneration in adult male rats. American Journal of Physiology. Endocrinology and Metabolism 291 E1074-E1082. (doi:10.1152/ajpendo.00040.2006)
Tovar S, Vazquez MJ, Navarro VM, Fernandez-Fernandez R, Castellano JM, Vigo E, Roa J, Casanueva FF, Aguilar E, Pinilla L et al. 2006 Effects of single or repeated intravenous administration of kisspeptin upon dynamic LH secretion in conscious male rats. Endocrinology 147 2696-2704. (doi:10.1210/en.2005-1397)

Received 20 July 2010

First decision 12 August 2010

Revised manuscript received 6 June 2011

Accepted 13 June 2011 